\section{Population size and viability}

SIR - Decimation and fragmentation of plant communities are a threat to the maintenance of biodiversity. As a result of genetic erosion or reduced availability of suitable pollen ${ }^{1}$, smaller populations can be expected to produce disproportionately fewer seeds until a critical population size is reached, beyond which seed production may be negligible and extinction inevitable (the Allee effect ${ }^{2}$ ).

Banksia is an important genus of 75 species in the vegetation of southern Australia. Some species are rare and on the verge of extinction. Banksias produce infructescences (cones) which bear follicles, each containing two seeds. Seeds are retained until the follicles open in response to fire or the cones begin to disintegrate after ten or more years. B. goodii is a woody prostrate species pollinated by mammals (honey possums) and birds (honeyeaters). Agriculture and road building have reduced the abundance of $B$. goodii to 16 known populations occurring in a $37 \times 13 \mathrm{~km}^{2}$ area north of Albany, Western Australia $\left(34^{\circ} 45^{\prime} \mathrm{S}, 117^{\circ} 40^{\prime} \mathrm{E}\right)$. Nine populations are small remnants on road verges.

We assessed all individuals of all known populations for seed production in September-October 1992. Small populations produced none or only a few seeds per unit canopy area (see figure). Effects of population size on seed production per unit area were present in the whole range of population sizes ( $b$ in the figure), indicating that even in the large populations seed production may still not be at its maximum. Resource differ-

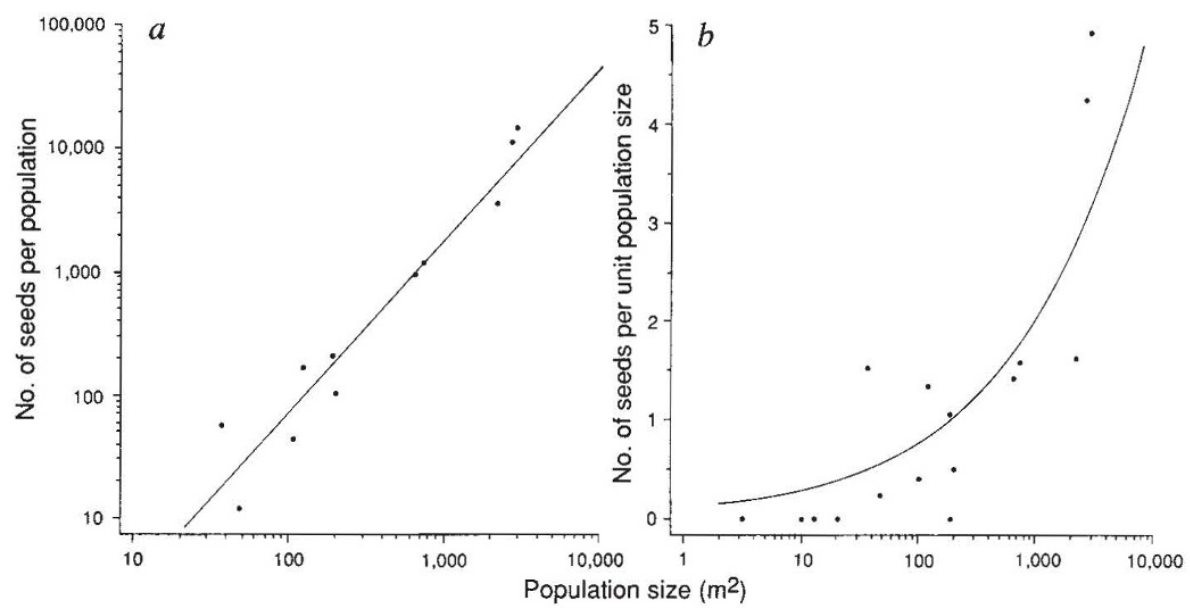

a, Total seed production per population $(Y)$ decreases more than proportionally with decline in population size $(X) . b$, In small populations seed production per unit canopy area is lower than in larger populations. Population size is gauged as $\Sigma(\pi / 4) D_{1} D_{2} C$, where $D_{1}$ is maximum diameter, $D_{2}$ that at right angles, and $C$ projective canopy cover. All but one population had not been disturbed for at least 20 years (no fires or soil disturbance) and all cones $<10$ years old were intact and retained all their seeds. To test for proportionality in a we used the model $Y=a X^{b}$, or $\log Y=a^{\prime}+b \log X$ (ref. 8). After omitting populations with no seeds we obtained: $\log Y=-0.99+1.43 \log X ; R^{2}=0.93, P<0.0001$; test on $H_{0}: b=1$, $\left.H_{1}: b>1: F=11.35, P=0.004\right)$. To avoid spurious correlations the line in $b$ is based on the regression equation in $a$. In $b$, populations with no seed production have been added. considered negligible. The sobering message is that a series of small populations may not have the same conservation value as a larger one with the same total population size, while there may be a threshold below which local extinction is inevitable.

Byron B. Lamont

School of Environmental Biology,

Curtin University of Technology,

PO Box U1987, Perth, Australia 6001

Peter G. L. Klinkhamer

Institute for Evolutionary and

Environmental Sciences.

University of Leiden,

PO Box 9516, 2300 RA Leiden,

The Netherlands

1. Rathke, B. in Pollination Biology (ed. Real, L.) 305-325 (Academic, New York, 1983)

2. Allee, W. C. Ecology 30, 395-397 (1949)

3. Ramsey, M. \& Vaughton, G. Aust. J. Bot. 39, 497-504 (1991).

4. Fuss, A. M. \& Sedgley, M. Ann. Bot. 68,377-384(1991)

5. Recher, H. F. \& Serventy, D. L. Conserv. Biol. 5, 90-102

(1991).

6. Lande, R. \& Barrowclough, G. F. in Viable Populations for Conservation (ed. Soulé, M. E.) 87-124 (Cambridge Univ. Press, 1987)

7. Lesica, P. \& Allendorf, F. W. Conserv. Biol. 6, 135-139 (1992).

8. Klinkhamer, P. G. L., de Jong, T. J. \& Meelis, E. Am. Nat. 135, 291-300 (1990).

\section{ATP in synapses}

SIR - Although we agree with McLachlan and Keast ${ }^{1}$ that "it would be unfortunate if the idea that ATP is commonly a cotransmitter at cholinergic synapses entered the textbooks", we think it would be equally unfortunate if their comments leave the impression that ATP cannot yet be accepted as a neurotransmitter in the peripheral or central nervous systems.

As pointed out by Benham ${ }^{2}$, the evidence is now overwhelming that ATP is a major ${ }^{3,4}$ vasoconstrictor substance released from noradrenergic sympathetic nerve terminals onto blood vessels. We $\mathrm{W}^{5}$ and Edwards et al. ${ }^{6}$ have demonstrated that ATP can also mediate fast ligandgated synaptic transmission at nervenerve synapses. Edwards et al. did not suggest that the ATP synaptic current they identified in slices of the medial habenulum derived from the known cholinergic input to this brain region, but there is no evidence against this (or any other) presynaptic origin.

We recorded ATP synaptic currents from noradrenergic coeliac ganglion neurons maintained in tissue culture and thus deprived of both their preganglionic cholinergic input and their postganglionic vascular targets. McLachlan and Keast find this result "unexpected" because only nicotinic fast synaptic potentials have been recorded from intact coeliac ganglia and because previous studies on other sympathetic ganglia showed that many noradrenergic 